\title{
STABILITY OF DETERMINACY AND INVERSE SPECTRAL PROBLEMS FOR JACOBI OPERATORS
}

\author{
RAFAEL DEL RiO AND Luis O. Silva
}

\begin{abstract}
This work studies the interplay between Green functions, the index of determinacy of spectral measures and interior finite rank perturbations of Jacobi operators. The index of determinacy quantifies the stability of uniqueness of solutions of the moment problem. We give results on the constancy of this index in terms of perturbations of the corresponding Jacobi operators. The permanence of the $N$-extremality of a measure is also studied. A measure $\mu$ is $N$-extremal when the polynomials are dense in $L_{2}(\mathbb{R}, \mu)$. As a by-product, we give a characterization of the index in terms of cyclic vectors. We consider a new inverse problem for Jacobi operators in which information on the place where the interior perturbation occurs is obtained from the index of determinacy.
\end{abstract}

Mathematics subject classification (2010): 41A10, 47B36, 33E30.

Keywords and phrases: Index of determinacy, density of polynomials, Green function, Jacobi operators.

\section{REFERENCES}

[1] N. I. AKHIEZER, On weighted approximations of continuous functions by polynomials on the entire number axis, Uspehi Mat. Nauk (N. S.) 11 (1956), no. 4(70), 3-43.

[2] N. I. AKHIEZER, The classical moment problem and some related questions in analysis, Translated by N. Kemmer. Hafner Publishing Co., New York, 1965.

[3] N. I. AKHIEZER, Theory of approximation, Dover Publications, Inc., New York, 1992. Translated from the Russian and with a preface by Charles J. Hyman, Reprint of the 1956 English translation.

[4] N. I. AkhieZer And I. M. Glazman, Theory of linear operators in Hilbert space, Dover Publications Inc., New York, 1993. Translated from the Russian and with a preface by Merlynd Nestell, Reprint of the 1961 and 1963 translations, Two volumes bound as one.

[5] A. BAKAN, On the completeness of algebraic polynomials in the spaces $L_{p}(\mathbb{R}, d \mu)$, Ukraïn. Mat. Zh. 61 (2009), no. 3, 291-301.

[6] A. BAKAn AND S. RUSCHEWEYh, Representation of measures with simultaneous polynomial denseness in $L_{p}(\mathbf{R}, d \mu), 1 \leqslant p<\infty$, Ark. Mat. 43 (2005), no. 2, 221-249.

[7] A. G. BAKAn, Polynomial density in $L_{p}(\mathbb{R}, d \mu)$ and representation of all measures which generate a determinate Hamburger moment problem, In Approximation, optimization and mathematical economics (Pointe-à-Pitre, 1999), pages 37-46. Physica, Heidelberg, 2001.

[8] A. G. BAKAN, A criterion for the density of algebraic polynomials in the spaces $L_{p}(\mathbb{R}, d \mu), 1 \leqslant p<$ $\infty$, Ukraïn. Mat. Zh. 55 (2003), no. 5, 701-705.

[9] A. G. BAKAN, An addition to S. N. Mergelyan's theorem on the denseness of algebraic polynomials in the space $C_{w}^{0}$, Ukraïn. Mat. Zh. 57 (2005), no. 7, 867-878.

[10] A. G. BAKAN, Representation of measures with polynomial denseness in $L_{p}(\mathbb{R}, d \mu), 0<p<\infty$, and its application to determinate moment problems, Proc. Amer. Math. Soc. 136 (2008), no. 10, 3579-3589.

[11] J. M. BEREZANS'KIĬ, Expansions in eigenfunctions of selfadjoint operators, Translated from the Russian by R. Bolstein, J. M. Danskin, J. Rovnyak and L. Shulman. Translations of Mathematical Monographs, vol. 17. American Mathematical Society, Providence, R. I., 1968. 
[12] C. Berg And J. P. R. Christensen, Density questions in the classical theory of moments, Ann. Inst. Fourier (Grenoble) 31 (1981), no. 3:vi, 99-114.

[13] C. BERG AND A. J. DURAN, The index of determinacy for measures and the $l^{2}$-norm of orthonormal polynomials, Trans. Amer. Math. Soc. 347 (1995), no. 8, 2795-2811.

[14] C. BERG AND A. J. DURAN, When does a discrete differential perturbation of a sequence of orthonormal polynomials belong to $l^{2}$ ?, J. Funct. Anal. 136 (1996), no. 1, 127-153.

[15] C. BERG AND A. J. DuRAN, Measures with finite index of determinacy or a mathematical model for Dr. Jekyll and Mr. Hyde, Proc. Amer. Math. Soc. 125 (1997), no. 2, 523-530.

[16] M. S. Birman And M. Z. Solomjak, Spectral theory of selfadjoint operators in Hilbert space, Mathematics and its Applications (Soviet Series), D. Reidel Publishing Co., Dordrecht, 1987. Translated from the 1980 Russian original by S. Khrushchëv and V. Peller.

[17] A. BORICHEV, On the closure of polynomials in weighted spaces of functions on the real line, Indiana Univ. Math. J. 50 (2001), no. 2, 829-846.

[18] A. Borichev AND M. Sodin, Density of polynomials and the Hamburger moment problem, C. R. Acad. Sci. Paris Sér. I Math. 327 (1998), no. 1, 11-16.

[19] R. DEl Rio, M. Kudryavtsev, And L. O. Silva, Inverse problems for Jacobi operators IV: Interior mass-spring perturbations of semi-infinite systems, Inverse Problems 33 (2017), no. 5, 055014, 30 pp.

[20] R. DEL RIO AND L. O. Silva, Spectral analysis for linear semi-infinite mass-spring systems, Math. Nachr. 288 (2015), no. 11-12, 1241-1253.

[21] G. FREUD, Orthogonale Polynome, Birkhäuser Verlag, Basel-Stuttgart, 1969. Lehrbücher und Monographien aus dem Gebiete der Exakten Wissenschaften, Mathematische Reihe, Band 33.

[22] F. GESZTESy AND B. SimOn, $m$-functions and inverse spectral analysis for finite and semi-infinite Jacobi matrices, J. Anal. Math. 73 (1997), 267-297.

[23] H. Hamburger, Über eine Erweiterung des Stieltjesschen Momentenproblems, Math. Ann. 82 (1921), no. 3-4, 168-187.

[24] T. Kato, Perturbation theory for linear operators, Springer-Verlag, Berlin, second edition, 1976. Grundlehren der Mathematischen Wissenschaften, Band 132.

[25] M. Langer And H. WoraceK, Stability of N-extremal measures, Methods Funct. Anal. Topology 21 (2015), no. 1, 69-75.

[26] N. K. NiKOLSKI, Operators, functions, and systems: an easy reading, vol. 1, volume 92 of Mathematical Surveys and Monographs, American Mathematical Society, Providence, RI, 2002. Hardy, Hankel, and Toeplitz, Translated from the French by Andreas Hartmann.

[27] M. PÉrez Riera AND J. L. VARONA Malumbres, On completeness of orthogonal systems and Dirac deltas, J. Comput. Appl. Math. 58 (1995), no. 2, 225-231.

[28] M. REED AND B. SIMON, Methods of modern mathematical physics. I, Academic Press Inc. [Harcourt Brace Jovanovich Publishers], New York, second edition, 1980. Functional analysis.

[29] M. RiESZ, Sur le problême des moments el le théorème de Parseval correspondant, Acta Litt. Acad. Sci. Szeged 1 (1923), 209-225.

[30] M. Rosenblum and J. Rovnyak, Topics in Hardy classes and univalent functions, Birkhäuser Advanced Texts: Basler Lehrbücher. [Birkhäuser Advanced Texts: Basel Textbooks]. Birkhäuser Verlag, Basel, 1994.

[31] B. Simon, The classical moment problem as a self-adjoint finite difference operator, Adv. Math. 137 (1998), no. 1, 82-203.

[32] G. TESCHL, Jacobi operators and completely integrable nonlinear lattices, vol. 72 of Mathematical Surveys and Monographs, American Mathematical Society, Providence, RI, 2000.

[33] P. YUdITSKII, Analytic perturbation preserves determinacy of infinite index, Math. Scand. 86 (2000), no. 2, 288-292. 